\title{
Development of Sensitive Holographic Devices for Physiological Metal Ion Detection
}

\author{
Sabad-e- Gul \\ Technological University Dublin, sabade.gul@mydit.ie \\ Suzanne Martin \\ Technological University Dublin, suzanne.martin@tudublin.ie \\ John Cassidy \\ Technological University Dublin, john.cassidy@tudublin.ie
}

See next page for additional authors

Follow this and additional works at: https://arrow.tudublin.ie/otpomcon

Part of the Optometry Commons, and the Physical Sciences and Mathematics Commons

\section{Recommended Citation}

Gul, S., Martin, S., \& Cassidy, J. (2017). Development of sensitive holographic devices for physiological metal ion detection. SPIE Nanoengineering: Fabrication, Properties, Optics, and Devices XIV, San Diego, California, USA, August 31st. 2017. doi:10.1117/12.2275734

This Conference Paper is brought to you for free and open access by ARROW@TU Dublin. It has been accepted for inclusion in Conference Papers by an authorized administrator of ARROW@TU Dublin. For more information, please contact arrow.admin@tudublin.ie, aisling.coyne@tudublin.ie,gerard.connolly@tudublin.ie. Funder: Technological University Dublin 
Authors

Sabad-e- Gul, Suzanne Martin, John Cassidy, and Izabela Naydenova

This conference paper is available at ARROW@TU Dublin: https://arrow.tudublin.ie/otpomcon/12 


\section{Development of sensitive holographic devices for physiological metal ion detection}

Sabad-e-Gul

Suzanne Martin

John Cassidy

Izabela Naydenova 


\title{
Development of sensitive holographic devices for physiological metal ion detection \\ Sabad-e-Gul ${ }^{1,3}$, Suzanne Martin ${ }^{1,3}$, John Cassidy ${ }^{2,3}$, Izabela Naydenova*1,3
}

${ }^{1}$ Centre for Industrial and Engineering Optics/School of Physics and Clinical \& Optometric

Sciences, College of Sciences and Health, Dublin Institute of Technology, Kevin Street, Dublin 8

${ }^{2}$ School of Chemical and Pharmaceutical Sciences, College of Sciences and Health, Dublin Institute of Technology, Kevin Street, Dublin 8

${ }^{3}$ FOCAS, Dublin Institute of Technology

*corresponding author: izabela.naydenova@dit.ie

\begin{abstract}
The development of selective alkali metal ions sensors in particular is a subject of significant interest. In this respect, the level of blood electrolytes, particularly $\mathrm{H}^{+}, \mathrm{Na}^{+}, \mathrm{K}^{+}$and $\mathrm{Cl}^{-}$, is widely used to monitor aberrant physiologies associated with pulmonary emphysema, acute and chronic renal failure, heart failure, diabetes.

The sensors reported in this paper are created by holographic recording of surface relief structures in a self-processing photopolymer material. The structures are functionalized by ionophores dibenzo-18-crown-6 (DC) and tetraethyl 4-tert-butylcalix[4]arene (TBC) in plasticised polyvinyl chloride (PVC) matrix. Interrogation of these structures by light allows indirect measurements of chemical analytes' concentration in real time. We present results on the optimisation and testing of the holographic sensor. A self-processing acrylamide-based photopolymer was used to fabricate the required photonic structures. The performance of the sensors for detection of $\mathrm{K}^{+}$and $\mathrm{Na}^{+}$was investigated. It was observed that the functionalisation with $\mathrm{DC}$ provides a selective response of the devices to $\mathrm{K}^{+}$over $\mathrm{Na}^{+}$and TBC coated surface structures are selectively sensitive to $\mathrm{Na}^{+}$. The sensor responds to $\mathrm{Na}^{+}$ within the physiological ranges. Normal levels of $\mathrm{Na}^{+}$and $\mathrm{K}^{+}$in human serum lie within the ranges $135-148 \mathrm{mM}$ and 3.5-5.3 $\mathrm{mM}$ respectively.
\end{abstract}

\section{Key words}

Biomedical sensors, Sensors, Holography, Photopolymers, Potassium ion detection, Sodium ion detection, Blood serum tests

\section{Introduction}

There is an urgent requirement for inexpensive mass producible clinical diagnostic devices that allow measurements on site. Much effort has been devoted to decreasing the expense and time allocated to measurement of physiologically important ions. The development of selective alkali metal ions sensors is a subject of significant interest because of their clinical relevance Biosensors are becoming an essential part of modern healthcare [1]. In the future, biosensor development will become even more essential due to the demand for personalizedmedicine, point-of care devices and cheaper diagnostic tools. Moreover, many challenges of the healthcare-system can only be solved by new sensor technologies. However, it is important to ensure that biomedical sensors are environmentally stable and and cost effective. Biosensor development is prompted by the discovery of new materials that can be used as functionalising materials [2]. Research aims at increasing sensitivity, reducing sample size, lowering operating costs and making single-use disposable devices and improving portability [3].

\footnotetext{
Nanoengineering: Fabrication, Properties, Optics, and Devices XIV, edited by Eva M. Campo, Elizabeth A. Dobisz, Louay A. Eldada, Proc. of SPIE Vol. 10354, 103540C · (C) 2017 SPIE - CCC code: 0277-786X/17/\$18 - doi: 10.1117/12.2275734 
The levels of blood electrolytes, particularly $\mathrm{H}^{+}, \mathrm{Na}^{+}, \mathrm{K}^{+}$and $\mathrm{Cl}^{-}$, are widely used to monitor aberrant physiologies associated with pulmonary emphysema, acute and chronic renal failure, heart failure, diabetes. Particularly $\mathrm{K}^{+}$ion analysis is challenging to detect due to interference from high concentrations of $\mathrm{Na}^{+}$in blood. Recently it has been found that crown ethers have a remarkable capacity to form stable complexes with certain cations, particularly with alkali and alkaline earth ions. In the present research, dibenzo-18-crown-6 was (DC) used as an ionophore to detect $\mathrm{K}^{+}$ions [4].

The sensor reported here is created by holographic recording of surface relief gratings in a self-processing photopolymer material. The gratings were functionalized by incorporation of a chelating agent - DC or TBC in plasticised polyvinyl chloride binder for the detection of potassium and sodium. Interrogation of these structures by light allows indirect measurements of chemical analytes' concentration in real time. These two ionophores have been previously widely used in the fabrication of ion selective electrode for potentiometric measurements [5][6][7].

\section{Fabrication of Photopolymer films}

\subsection{Materials and Methods}

The acrylamide based photopolymer was prepared as described in Table 2 . The components were well mixed in water by using a magnetic stirrer. All the materials used in this work were of analytical grade purchased from Sigma Aldrich without any purification.

Table 1.The amount of component's added in the photopolymer solution

\begin{tabular}{|c|c|c|}
\hline Components & Amount (g) & $\begin{array}{c}\text { Amount (\% w/w) in } \\
\text { dry layer }\end{array}$ \\
\hline $\begin{array}{c}\text { Acrylamide, AA } \\
\text { BA }\end{array}$ & 1.0 & 24.5 \\
\hline $\begin{array}{c}\text { Polyvinyl alcohol (10\% wt/wt) } \\
\text { PVA }\end{array}$ & 1.75 & 4.9 \\
\hline $\begin{array}{c}\text { Triethanolamine TEA } \\
\text { Erythrosine B dye (0.01wt. } \% \\
\text { ErB }\end{array}$ & 0.0044 & 27.5 \\
\hline
\end{tabular}

\subsubsection{Photopolymer solution and layer preparation}

All the samples were prepared under ambient laboratory conditions [temperature $18-21^{\circ} \mathrm{C}$; relative humidity $(\mathrm{RH}), 40-60 \%$ as follows. PVA (MW 9,000-10,000) was dissolved in distilled water while heated at $70^{\circ} \mathrm{C}$ to obtain a $10 \mathrm{wt}$. \% PVA aqueous solution. Crystals of Erythrosine B $(\mathrm{ErB})$ were dissolved in water at room temperature to obtain dye stock solution with the desired dye concentration $(1.1 \mathrm{mM})$. The TEA was added into the PVA solution. Finally, AA and BA were added as the two monomers, along with the ErB solution. After mixing for 1 hour all components were fully dissolved. [8]. 
$300 \mu$ volume of photopolymer solution was spread evenly on a glass slide of dimensions 7.6 $\mathrm{cm} \times 2.6 \mathrm{~cm}$. The coated glass slide was placed on a levelled surface and allowed to dry in dark for typically 5-6 hours. The thickness of the dry sample was $30 \pm 3 \mu \mathrm{m}$ [9].

\subsection{Construction of Surface Relief Holograms}

A two-beam holographic optical setup used to record the holographic gratings is shown in Figure 1. The angle between the two-beams was set as $9.16^{\circ}$ in order to obtain an interference pattern with spatial frequency of 300 lines $/ \mathrm{mm} \pm 10$ lines $/ \mathrm{mm}$. Nd: YVO4 laser emitting at $532 \mathrm{~nm}$ (Coherent, Model Verdi 5w) was used to record the transmission holographic gratings. The recording intensity was $10 \mathrm{mWcm}^{-2}$ and the exposure time was 100 seconds. The recording conditions were optimised for achieving maximum surface relief modulation. Details of the optimisation process were reported previously [10]. To obtain an angular selectivity curve of a recorded grating, a s- polarized Helium-Neon laser (He-Ne) (Uniphase Model No 106-1) of wavelength $633 \mathrm{~nm}$ was used as a probe beam incident at Bragg angle to the grating (as shown in figure 1) [11]. The intensity of the 1st order diffracted beam was measured using an optical power meter to determine the diffraction efficiency of the recorded gratings. The process of the grating formation was reported previously [10] [12].

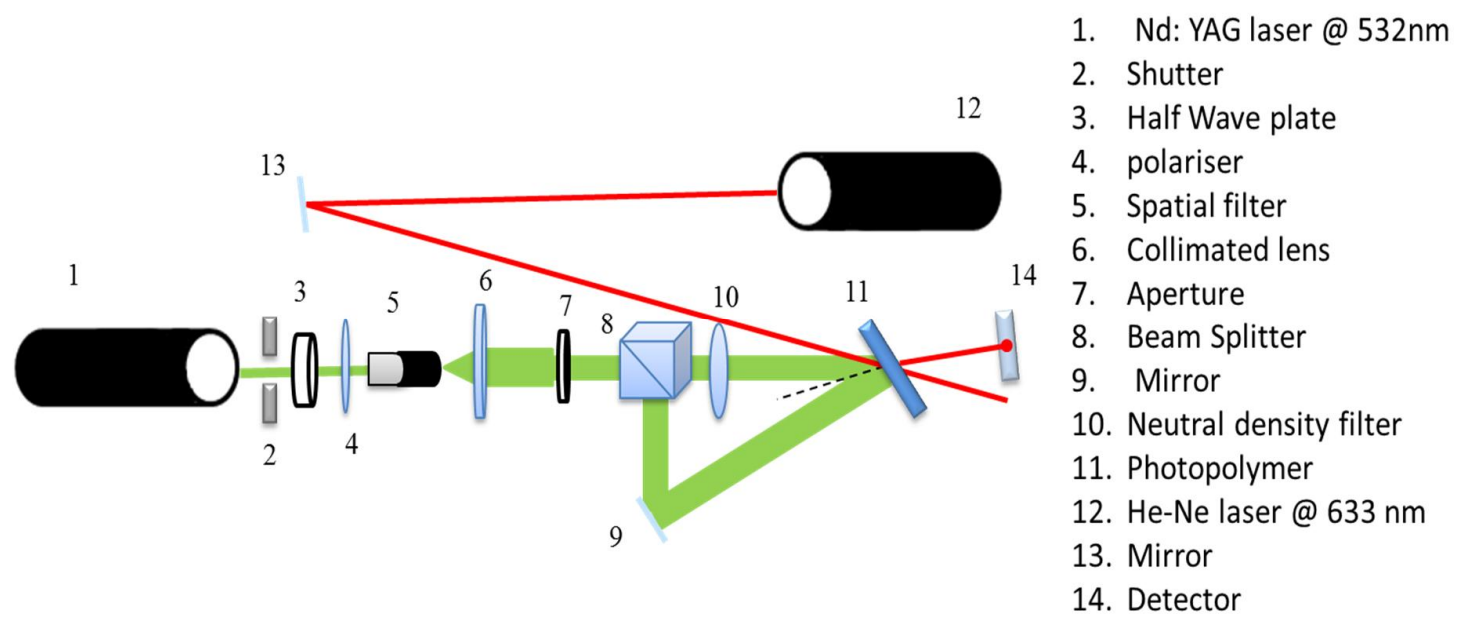

Figure 1. Experimental set-up for recording transmission holograms

\subsection{Functionalization by Dibenzo-18-crown-6 (DC) or tetraethyl p-tert-butylcalix [4] arene (TBC)}

The target ions in this research are potassium and sodium. Potassium and sodium ions are most commonly assayed by clinical laboratories. DC provides highly selective binding to potassium ions, because the 18-crown[6]ether cavity matches the size of potassium ions specifically as well as provides ion-dipole interaction with potassium ions [5]. A new class of ionophores, calixarenes, was introduced after 1990s. $\mathrm{Na}^{+}$selective membranes incorporated TBC known as one of the best sodium ionophores. Due to the well-defined three dimensional structure and capability to selective introduction of different receptor groups, calix[4] arene is a very promising starting material for synthetic ionophores being potentially selective to various ions. 
The surface holograms were functionalised with Calixarene ionophore immobilised in the PVC plasticised matrix [13], [14] or dibenzo-18-crown-6 [15]. The composition of chemicals was taken during this experiment are presented in the table 2 below.

Table 2. The amount of components' added in the photopolymer solution

\begin{tabular}{|l|c|c|}
\hline Components & Amounts(g) & $\begin{array}{c}\text { Amount (\% w/w) } \\
\text { in dry layer }\end{array}$ \\
\hline Polyvinyl Chloride (PVC) & 0.3 & 20 \\
\hline $\begin{array}{l}\text { Dioctyl terephthalate plasticizer } \\
\text { (DOTP) }\end{array}$ & 0.6 & 40 \\
\hline Dibenzo-18-crown-6 (DC) & 0.1 & 6.6 \\
\hline $\begin{array}{l}\text { tetraethyl 4-tert-butylcalix[4]arene } \\
\text { Ionophore (TBC) }\end{array}$ & 0.1 & 6.6 \\
\hline Sodium tetraphenylborate & 0.05 & 3.3 \\
\hline
\end{tabular}

All the components were stirred for 2 hours in $20 \mathrm{ml}$ of tetrahydrofuran (THF) at $60^{\circ} \mathrm{C}$ until all the chemicals completely dissolved in the mixture. Then this solution was spin coated on the SRG at 1000rpm and the solvent allowed to evaporate. Next the gratings were exposed to the $\mathrm{K}^{+}$and $\mathrm{Na}^{+}$to check the response of the sensors for different time intervals and the performance of the sensors for detection of $\mathrm{K}^{+}$and $\mathrm{Na}^{+}$was investigated.

\section{Results and Discussions}

\subsection{Diffraction efficiency and angular selectivity studies}

Figure 2 shows the diffraction efficiency as a function of angle of rotation for the gratings at different stages of the experiment i.e. before thermal treatment, after thermal treatment, after coating with the DC functionalising material, and after exposure to the analytes. A maximum diffraction efficiency of the photopolymer layers of $60 \%$ was achieved immediately after holographic recording and as discussed in table 3 . This value is due to the volume diffraction grating since at this stage the surface relief grating has negligible amplitude $(<1 \mathrm{~nm})$. After thermal treatment the diffraction efficiency decreased to $35 \%$ and a shift of the Bragg angle was observed as can be seen in the figure 2 . The shift is most probably due to an increase in the effective refractive index of the photopolymer layer, as the density of the layer is visibly enhanced after thermal treatment. Other possible causes are shrinkage of the layer and a change of the spatial frequency of the structure. The Bragg angle measurement was then taken for layers functionalised with analyte sensitive materials. A further decrease in the diffraction efficiency was seen at this point due to substitution of the air in the troughs with material with higher refractive index. The DC and TBC in PVC almost fully cover the surface relief structure as was observed in AFM images. 


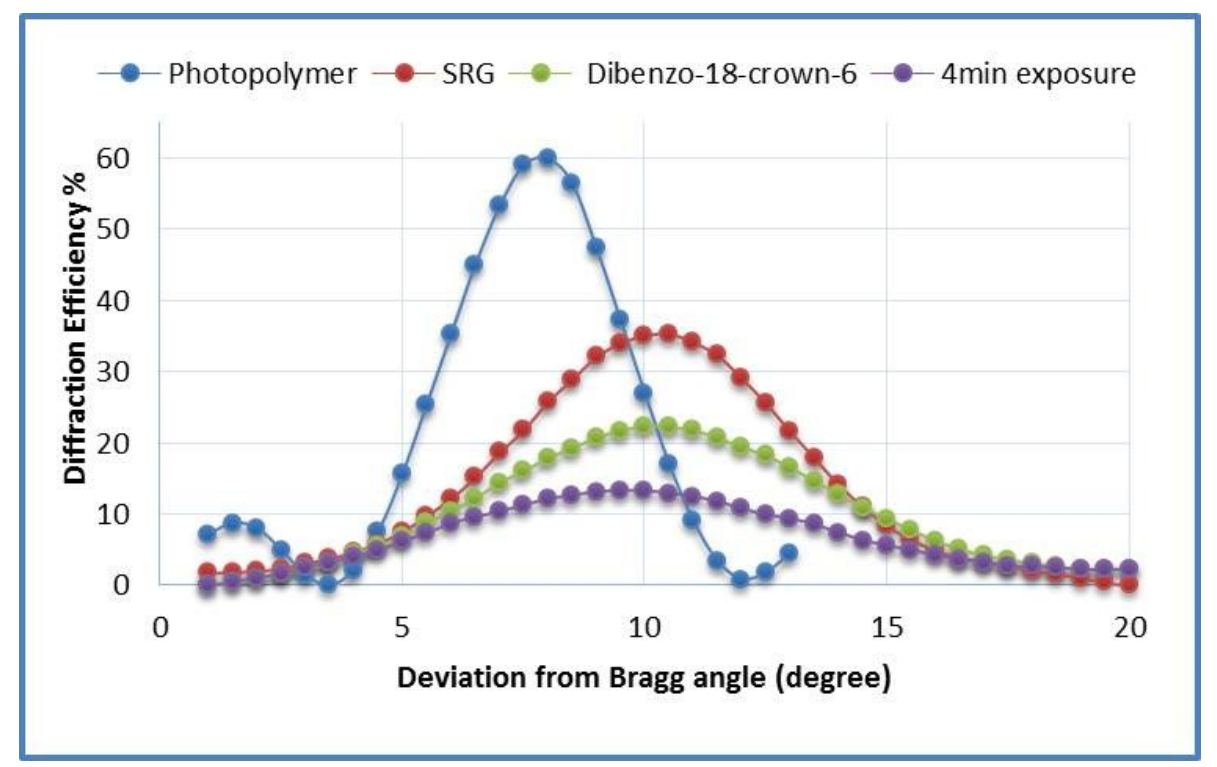

Figure2. Bragg curves with spatial frequency centred at $300 \mathrm{l} / \mathrm{mm}$ recorded in layers with thickness of 30 $\mu \mathrm{m}$ on a glass slide taken for the photopolymer before and after thermal treatment, after spin coating with dibenzo-18-crown-6 (DC) functionalising material and after exposure to analyte $\mathrm{K}^{+}$

\section{Sensitivity and selectivity Results of $\mathrm{K}^{+}$and $\mathrm{Na}^{+}$}

\subsection{Selectivity}

In order to determine the selectivity of the proposed holographic biosensor water solutions of $\mathrm{KCl}$ and $\mathrm{NaNO}_{3}$ were prepared. Crown ethers are known for their property of forming stable complexes with alkali metal ions due to the close fit of the cation to the crown ether's cavity. Inspection of Figure 3(a) shows that the dibenzo-18-crown- 6 on exposure to $\mathrm{K}^{+}$ions gives dominant response over $\mathrm{Na}^{+}$ion, while the hologram showed little response in the reference experiment, where the sample was exposed to water [17]. The normalised diffraction efficiency drops from 1 to 0.6 for $\mathrm{K}^{+}$, whereas for $\mathrm{Na}^{+}$it drops down only 1 to 0.9 .

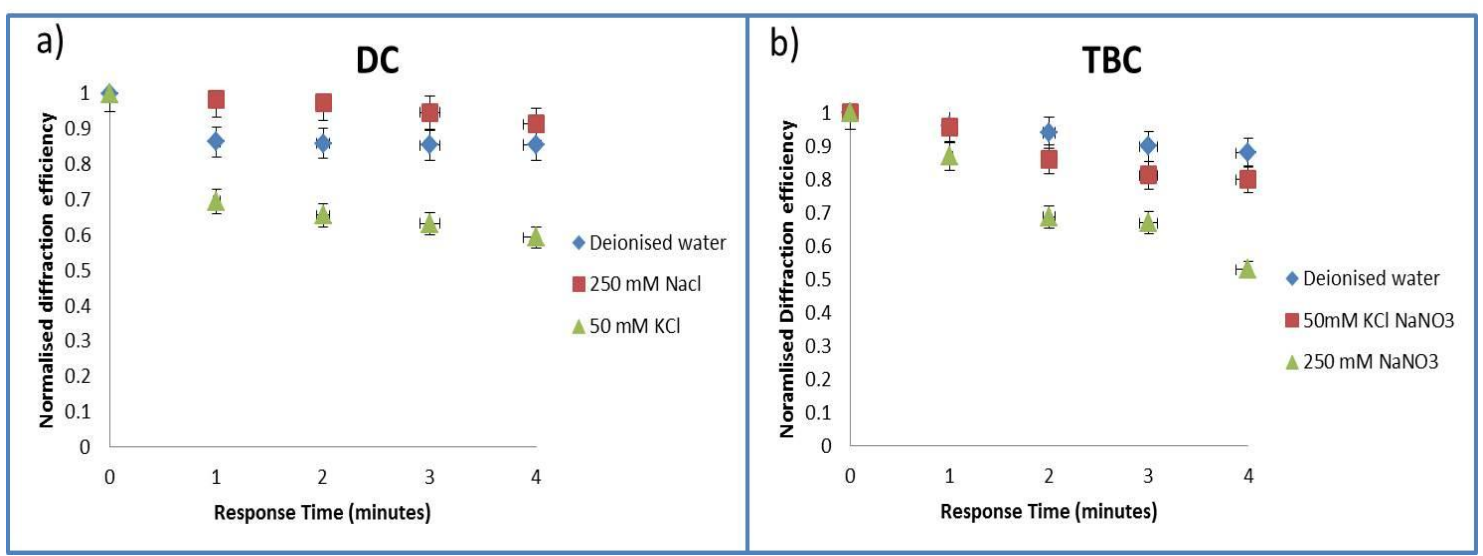

Figure3. Comparison of relative response in terms of normalised DE change of (a) DC with $250 \mathrm{mM}$ $\mathrm{NaCl}, 50 \mathrm{mM} \mathrm{KCl}$ and deionised water and (b) TBC structures with $50 \mathrm{mM} \mathrm{KCl,} 250 \mathrm{mM} \mathrm{NaNO}$, and deionised water

In Figure 3(b) shows that the TBC on exposure to $\mathrm{Na}^{+}$ions give dominant response over $\mathrm{K}^{+}$ ion concentration, while the hologram showed little response to water. The diffraction efficiency drops for $\mathrm{Na}^{+} 1$ to 0.52 , whereas for $\mathrm{K}^{+}$it drops down only 1 to 0.8 . 


\subsection{Sensitivity}

Figure 3(a), shows the results from exposure of the DC coated layers to a solution of $\mathrm{KCl}$. The concentrations of the analyte were chosen to cover the physiological range of $\mathrm{K}^{+}$present in blood serum. Total body stores approximately $50 \mathrm{mmol} / \mathrm{Kg}^{-1} \mathrm{~K}^{+}$and the normal $\mathrm{K}^{+}$level is 3.5-5.0 $\mathrm{mmol} / \mathrm{L}$ [18]. It can be seen that after exposure for four minutes concentration as low as $10 \mathrm{mM}$ are detectable.



Figure4. Normalised diffraction efficiency change response DC and TBC plasticised PVC photonic structures (a) KCl exposure to $(10-50 \mathrm{mM})$ (b) $\mathrm{NaNO}_{3}$ exposure to physiological levels $(130 \mathrm{mM}-150 \mathrm{mM})$

Solutions of $\mathrm{NaNO}_{3}$ were prepared with three different molar concentrations 130, 140 and $150 \mathrm{mM}$. The sensor based on the TBC ionophore was exposed to prepared solutions as shown in figure 4 (b). The concentrations of the analyte were chosen to cover the physiological range of $\mathrm{Na}+$ present in blood serum. Normal levels of $\mathrm{Na}^{+}$in human serum lie in the range 135-148 $\mathrm{mM}$ [18]. It can be seen that after exposure for four minutes concentration as low as $130 \mathrm{mM}$ are detectable.

\section{Conclusions}

Holographic sensor for the detection of different metal ions was prepared by functionalisation of surface relief structures with dibenzo-18-crown-6 or 4-tert-butylcalix[4]arene. Dibenzo18-crown-6 provides a selective response of the devices to $\mathrm{K}^{+}$, whereas for tetraethyl 4-tertbutylcalix[4] arene there is a dominant response for $\mathrm{Na}^{+}$. The sensor responds to $\mathrm{Na}^{+}$within the physiological ranges. Further work will be carried out in order to achieve the normal ranges of $\mathrm{K}^{+}$by varying the amounts of chelating compound or by changing the matrix permeability. This novel transduction device gives fast response and potentially this study can lead to the development of low cost senors that can be integrated in portable devices.

\section{Acknowledgements}

This work supported by DIT Fiosraigh Scholarship of SG. The authors express their gratitude to Focas Research Institute, DIT for the technical support. The authors also acknowledge the support of SPIE for providing a travel grant to SG to attend conference Optics and Photonics. 


\section{References}

[1] J. Melorose, R. Perroy, and S. Careas, Biomedical Sensors, vol. 1. New York: Momentum press, 2015.

[2] J. Ponmozhi, C. Frias, T. Marques, and O. Frazao, "Smart sensors/actuators for biomedical applications: Review,” Meas. J. Int. Meas. Confed., vol. 45, no. 7, pp. 1675-1688, 2012.

[3] J. Bujes-Garrido and M. J. Arcos-Martínez, "Disposable sensor for electrochemical determination of chloride ions," Talanta, vol. 155, pp. 153-157, 2016.

[4] A. G. Mayes, J. Blyth, and .R B. Millington, and C. R. Lowe, "Metal Ion-Sensitive Holographic Sensors," vol. 74, no. 15, pp. 3649-3657, 2002.

[5] G. Olsen, J. Ulstrup, and Q. Chi, "Crown-Ether Derived Graphene Hybrid Composite for MembraneFree Potentiometric Sensing of Alkali Metal Ions," ACS Appl. Mater. Interfaces, vol. 8, no. 1, pp. 3741, 2016.

[6] V. K. Gupta, M. R. Ganjali, P. Norouzi, H. Khani, A. Nayak, and S. Agarwal, "Electrochemical Analysis of Some Toxic Metals by Ion-Selective Electrodes," Crit. Rev. Anal. Chem., vol. 41, no. 4, pp. 282-313, 2011.

[7] R. M. El Nashar, H. A. A. Wagdy, and H. Y. Aboul-Enein, “Applications of calixarenes as potential ionophores for electrochemical sensors," Curr. Anal. Chem., vol. 5, no. 3, pp. 249-270, 2009.

[8] I. Naydenova, E. Mihaylova, S. Martin, and V. Toal, "Holographic patterning of acrylamide-based photopolymer surface.," Opt. Express, vol. 13, no. 13, pp. 4878-4889, 2005.

[9] R. Jallapuram, I. Naydenova, V. Toal, S. Martin, and R. Howard, "Spatial Frequency Response of Acrylamide Based Holographic Photopolymer Spatial frequency response of Acrylamide based holographic photopolymer," Laser Appl. Opt. Metrol., pp. 275-279, 2003.

[10] K. Trainer, K. Wearen, D. Nazarova, I. Naydenova, and V. Toal, “Optimization of an acrylamide-based photopolymer system for holographic inscription of surface patterns with sub-micron resolution,” $J$. Opt., vol. 124012, 2010.

[11] D. Cody, I. Naydenova, and E. Mihaylova, "Diacetone acrylamide-based non-toxic holographic photopolymer," Proc.SPIE 8429, pp. 0-7, 2012.

[12] I. Naydenova, E. Mihaylova, S. Martin, and V. Toal, "Holographic patterning of acrylamide - based photopolymer surface," Opt. Express, vol. 13, no. 13, pp. 3427-3435, 2005.

[13] P. Bühlmann, E. Pretsch, and E. Bakker, "Carrier-based ion-selective electrodes and bulk optodes. 2. Ionophores for potentiometric and optical sensors," Chem. Rev., vol. 98, no. 4, pp. 1593-1688, 1998.

[14] E. Malinowska, L. Gawart, P. X. Parzuchowski, G. Rokicki, and Z. Brzozka, "Novel approach of immobilization of calix[4]arene type ionophore in 'self-plasticized' polymeric membrane," Anal. Chim. Acta, vol. 421, no. 1, pp. 93-101, 2000.

[15] W. Hiller, S. Frey, J. Strahle, G. Bocheb, W. Zargesb, K. Harms, M. Marsch, R. Wollertb, and K.Dehnicke, "Die Kristallstrukturen von (Li3(12-Krone-4)2[HC(CN)2]3\}, [HC(CN)2]) und $(\mathrm{Na}[\mathrm{N}(\mathrm{nBu}) 4],[\mathrm{HC}(\mathrm{CN}) 2] ,2 . \mathrm{THF}\}, "$ Chem. Ber., vol. 3, pp. 87-92, 1992.

[16] H. Akbari, I. Naydenova, M. Kennedy, J. Doran, and S. Martin, "Design and Study of Acrylamidebased Photopolymer Holographic Optical Elements for Solar Application,” Sustain. Energy Storage, vol. 2, pp. 6-10, 2013.

[17] B. Madrigal González, G. Christie, C. A. B. Davidson, J. Blyth, and C. R. Lowe, "Divalent metal ionsensitive holographic sensors," Anal. Chim. Acta, vol. 528, no. 2, pp. 219-228, 2005.

[18] C. Burtis, A, R. Edwrd, and D. Bruns, E, Fundamentals of Clinical Chemistry :6th Ed, no. August. Philadelphia USA: SAUNDERS Elsevier, 2001. 